\title{
Supporting Information in
}

\section{THE MOLECULAR ARCHITECTURE OF NANOCAPSULES, BILAYER ENCLOSED SOLID PARTICLES OF CISPLATIN}

Vladimir Chupin, Anton I. P. M. de Kroon, and Ben de Kruijff
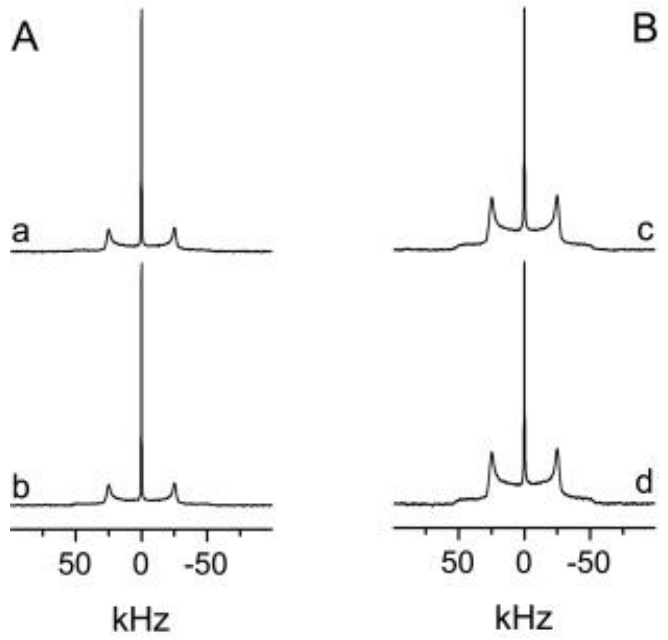

Figure 1S. (A) ${ }^{2} \mathrm{H}$ NMR spectra of ${ }^{2} \mathrm{H}$ labeled cisplatin in nanocapsules recorded after preparation (a) and after storage during 3 weeks at $4^{\mathrm{O}} \mathrm{C}$ (b). (B) ${ }^{2} \mathrm{H}$ NMR spectra of the crystalline ${ }^{2} \mathrm{H}$ labeled cisplatin dispersed in deuterium depleted water $(200 \mathrm{mM})$ recorded after preparation (c) and after storage during 3 weeks at $4^{\mathrm{O}} \mathrm{C}(\mathrm{d})$.

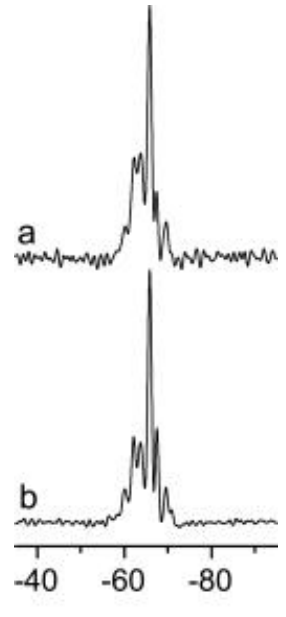

ppm

Figure 2S. MAS ${ }^{15} \mathrm{~N}$ NMR spectra of a lyophilized sample of an equilibrated aqueous solution of cisplatin (a) and nanocapsules (b).

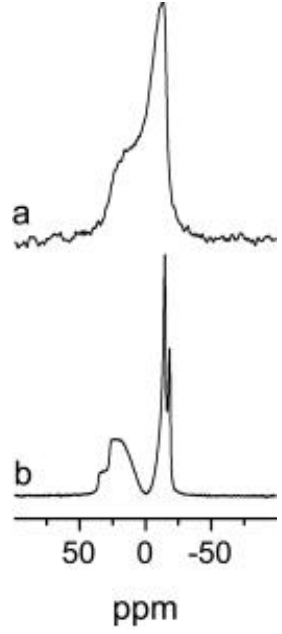

Figure 3S. ${ }^{31} \mathrm{P}$ NMR spectra of nanocapsules (a) and of an equimolar mixture of DOPC/DOPS dispersion in water (b). The spectra were recorded using $\mathrm{CP}$ with a contact time of $10 \mathrm{~ms}$. Reduced intensity around the isotropic position in (b) indicates increase mobility of phospholipids in (b) compared with (a) (see ref.') 


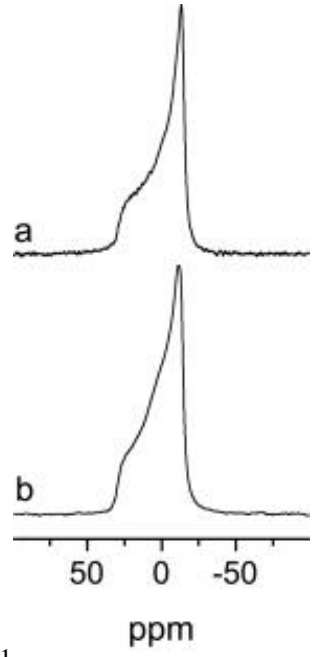

Figure S4. ${ }^{31} \mathrm{P}$ NMR spectra of a dispersion of an equimolar mixture of DOPC/DOPS dispersion in aqueous solution of cisplatin (a) and of a dispersion of an equimolar mixture of the DOPC/DOPS-cisplatin complex dispersion in water (b).

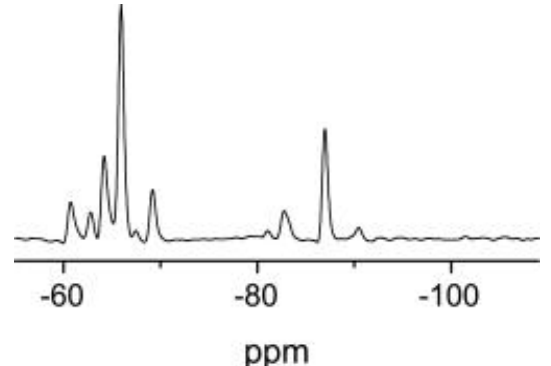

Figure S5. ${ }^{15} \mathrm{~N}$ NMR spectrum of ${ }^{15} \mathrm{~N}$ labeled cisplatin in aqueous solution after disruption of the lipid coat by sonication. 